\title{
Ultrasound Assessment of Diaphragmatic Thickness in Chronic Obstructive Pulmonary Disease Patients as a Predictor for Disease Severity
}

\author{
Tarek S. Essawy ${ }^{\text {a, }}$ Abdelsadek H. AL-Arag ${ }^{\text {a }}$, Hany H. Mousa ${ }^{\text {b }}$, Mona Abd El-Sattar ${ }^{\text {b }}$, Rehab S. \\ ELSawy $^{\text {a }}$
}

a Department of chest, Faculty of Medicine, Chest Benha University, Egypt.

${ }^{\mathrm{b}}$ Department of chest, Faculty of Medicine, Kafrelsheikh University, Egypt.

Correspondence to: Mona Abd El-Sattar, Department of chest, Faculty of Medicine, Kafrelsheikh University, Egypt.

Email:

dr.mona_abdelsattar@yahoo.com

Received: 13 February 2021

Accepted: 12 April 2021

\section{Abstract:}

Background and objectives: COPD patients usually had an imbalance in the load/capacity ratio of the respiratory muscles. This study aimed to use of ultra-sonographic (U/S) techniques for the assessment of diaphragmatic thickness of the diaphragm (TD) at different lung volumes in COPD patients, and its relation with severity of the disease. Methods A Case control study conducted on 100 subjects at outpatient clinics of Benha University Hospitals and Kafrelsheikh University Hospitals during the period from March, 2020 to December, 2020; 80 patients with clinically stable chronic obstructive pulmonary disease (COPD), were diagnosed and classified into four groups according to GOLD 2020: Group A COPD): 20 cases, Group B COPD): 20 cases, Group C COPD): 20 cases, Group D COPD): 20 cases. U/S was used for assessment of diaphragmatic thickness (TD) and diaphragmatic thickness fraction (TF) at different lung volumes in COPD subgroups, and correlated with severity of the disease and 20 apparent healthy control group. Results: In total 4 potentially relevant publications were included, the studies showed decrease in diaphragmatic thickness, thickness fraction and excursion in copd patients in comparison with normal subjects specially groups B and D COPD. Conclusion: Ultrasound is a non-invasive, simple and available bedside diagnostic tool for outpatient clinic examination of COPD patients for severity detection.

Key words: ultrasound, diaphragmatic thickness, COPD 


\section{Introduction:}

Chronic obstructive pulmonary disease (COPD) is a progressive disease characterized by incomplete reversible airflow limitation (1). COPD results from a complex interaction between genes and the environment. Cigarette smoking is the leading environmental risk factor for COPD (2). Dyspnea and exercise intolerance might result from an imbalance in the load/capacity ratio of the respiratory muscles in COPD patients.

Chronic airflow limitation imposes a load on respiratory muscles, flattening of the diaphragm and reducing its ability to generate tension. Various other factors can impair respiratory muscle function in COPD patients, including activation of proteases, oxidative stress, malnutrition, ageing, and comorbidityrelated systemic factors; however, changes in chest wall geometry and diaphragm position are the most commonly recognized and studied mechanisms contributing to respiratory muscle dysfunction. (3), the impairment of diaphragm is suggested to be an important factor, which is associated with alterations in the principal pulmonary function parameters such as FEV1. (4)

The use of ultra-sonographic (U/S) techniques for the assessment of diaphragmatic thickness (TD) and thickness fraction (TF) at different lung volumes in healthy and diseased individuals was proposed (5), to assess the diaphragmatic function in COPD patients and its relation with severity of the disease.

\section{Subjects and methods:}

A Case control study conducted on100 subject at outpatient clinics of Benha University hospitals and Kafrelsheikh University hospitals during the period from March, 2020 to December,2020; (80) patients with clinically stable chronic obstructive pulmonary disease (COPD), during their follow up in the outpatient clinic of Chest Department of Benha and Kafrelsheikh University Hospitals and 20 healthy volunteers with age and sex matched included as a control group.

These COPD group's patients were diagnosed and classified into four groups according to GOLD 2020 as following:

- Group A COPD): 20 cases

- Group B COPD): 20 cases

- Group C COPD): 20 cases

- Group D COPD): 20 cases

Inclusion criteria: Confirmed cases of stable COPD diagnosed according to GOLD 2020

(1) in different stages of severity through the following:

1. Full history taking including,

2. General and local chest examination

3. Simple spirometry to confirm COPD based on GOLD, 2020 : COPD 
patients are confirmed by spirometry (post bronchodilator forced expiratory volume 1(FEV1)/ forced vital capacity $(\mathrm{FVC})<0.70)$

-The severity of the COPD was based on $\boldsymbol{G O L D}, 2020$ report depends on:

A- PFT: spirometry with measuring of (FEV1, FEV1/FVC, FVC)

B-Dyspnea severity according to modified British Medical Research Council scale (mMRC) and (CAT) score

C-frequency of exacerbation per year.

D-combined copd assessment (ABCD categorization tool) which combines all the above tools

4.Oxygen saturation measurement by pulse oximetry

5.Laboratory work up(CBC, Liver function, Kidney function, $\mathrm{ABG}$ )

6.Plain chest $\mathrm{X}$ - ray (posterior-anterior and lateral views).

7.Ultrasonography of the diaphragm: By Philips Hd5 Color Doppler Ultrasound Machine, 2013 with (C 2-5 MHz) curved low frequency and (L 12-3 MHz) linear high frequency probe transducers for diaphragm and for intercostal muscles using the linear one.
Measured variables: diaphragmatic thickness and thickening fraction of the diaphragm were assessed through this technique: The intercostal approach is performed with a (10-15- MHz) linear array transducer positioned in a cranio-caudal direction and perpendicular to the skin in the zone of apposition between the mid-axillary and antero-axillary line, in the 8th to 11th intercostal space (Fig. 1) (6), measuring diaphragm thickness perpendicular to its fiber direction between the pleural and peritoneal membrane, and not including the membranes (Fig. 1). The lower limit for normal diaphragm thickness is around $1.5 \mathrm{~mm}$ in healthy subjects. Thickening fraction of the diaphragm (TFdi) is calculated in B-mode or M-mode as the percentage inspiratory increase in diaphragm thickness relative to end-expiratory thickness during tidal breathing (TFdi) or maximal inspiratory effort (TFdi $(\max )):$ TFdi $=$ (end-inspiratory thickness - end-expiratory thickness)/ endexpiratory thickness $\times 100 \%$ (Fig. 1). (7)

Exclusion criteria: Subjects were excluded from the study if they had any of the following conditions:

1. Patients with other chest diseases.

2. Patients with neuromuscular diseases or chest wall deformity. 
3. Patients with systemic diseases affecting muscles function e.g. endocrine, neoplastic and metabolic disorders or on drugs causing myopathy like long-term corticosteroids.

4. Patients with any cause of increased intra-abdominal pressure

5. Patients with history of recent upper abdominal or thoracic surgery.

6. Subjects refusing to participate in the study.

Ethical approval: the study was conducted at Chest medicine department of Benha and Kafrelsheikh University Hospitals after approval of the research Ethical committee at faculty of medicine, Benha University (RECFOMBU).

Statistical analysis: The collected data were coded, processed and analyzed using the SPSS (Statistical Package for Social Sciences) version 22 for Windows ${ }^{\circledR}$ (IBM SPSS Inc. (Chicago, IL, USA).

Probability value (P-value) was interpreted as follow:

- Non-significant if the $p$ value is $>0.05$

- Significant if the $\mathrm{p}$ value is $\leq 0.05$.

- Highly significant if the $\mathrm{p}$ value $<0.001$.

\section{The following tests were done:}

1) One-way analysis of the variance (Oneway ANOVA) was used to compare between three or more independent groups of normally distributed variables

2) Independent samples t-test was used to compare between two independent groups of normally distributed variables

3) Chi square test $\left(\chi^{2}\right)$ and Fisher test used to calculate difference between qualitative variables as indicated.

\section{4) Receiver operating characteristic (ROC) analysis:}

Test characteristics were estimated by ROC curve and included best cutoff value, AUC, its standard error (SE), and $P$-value. In addition, to assess the effectiveness of the test, estimates as sensitivity, specificity, positive predictive value (PPV), negative predictive value (NPV), and accuracy were calculated at the optimal cutoff.

\section{Results}

The total number of studied COPD group was 80 patients 70 male and 10 female, their age ranged from (49-76) with mean \pm SD (59.86 $\pm 6.53)($ table 1$)$

The smoking index of the studied groups was ranged from (17 to120) with Mean \pm SD $60.65 \pm 23.06$ and there were $(56.25 \%)$ current smoker, (36.25\%) ex-smoker and $(7.5 \%)$ patients were nonsmoker. (Table 2) 
Current smoker patients were higher in-group $\mathrm{C}$ and D in comparison to other groups (37\%) and $(33 \%)$ patients respectively. In addition, ex-smoker patients more in groups A (33\%) and $B(45 \%)$ and non-smoker were more ingroup A COPD. (Table 2).

Groups B and D copd patients showed more reduction in FEV1 than other subgroups .In addition, mMRC scale grading was increased with increasing COPD severity as shown in group D mMRC (grade 2 was 3 cases (15\%),grade 3 was 12 cases( 60\% )and grade 4 was 5 cases $(25 \%)$. While CAT scale was, significally higher in groups $\mathrm{B}, \mathrm{D}$, which is compatible with COPD classification of severity (table 3 ).

There was a statistical significance difference between COPD group (80 patients) and control group as regard diaphragmatic thickness at (TLC and FRC), diaphragmatic thickness fraction $(\mathrm{TF})$ (p value $<0.001$ ) (table 4).

In this study ultra-sonographic assessments of diaphragmatic thickness at (TILC (mm), FRC $(\mathrm{mm})$ ) and diaphragm thickness fraction, there was a statistically significant reduction in diaphragmatic thickness in (TILC (mm), FRC (mm), TF) within COPD subgroups with most reduction in groups $\mathrm{B}$ and $\mathrm{D}(\mathrm{P}$ value $<0.001)$.(Table 5) While in a comparison between copd subgroups and control group, there was no statistical significant difference between group $\mathrm{A}$ and control in measured parameters' $p$ value $(\mathrm{P} 1=0.922)$.

However, other groups B, C and D showed decrease in diaphragmatic thickness in (TILC $(\mathrm{mm})$, FRC (mm), TF) with increasing severity which more obvious in group D copd ( $\mathrm{P}$ value $<0.001)$.(table 5)

In a statistical comparison between different ultra-sonographic parameter to differentiate between control \& all COPD patients (No.80), the cut-off point to differentiate between copd groups and control group as regard to thickness fraction was $0.927 \mathrm{~cm}$ with sensitivity $75 \%$ and specificity 80\%.(Table 6),(figure 2)

In addition, for each group separately as shown in (table 7), group A showed no statistical difference $(\mathrm{P}$ value $=0.839)$ with sensitivity $70 \%$ and specificity $40 \%$. (Figure 3)

While group B was significant ( $\mathrm{P}$ value < 0.001 ) with sensitivity $95 \%$ and specificity 95 $\%$. (Figure 4).Group C was statistically significant $(\mathrm{P}$ value $<0.001)$ with sensitivity $60 \%$ and specificity 95\%. (Figure 5) and finally group $\mathrm{D}$ showed statistical difference (P value < 0.001$)$ with specificity $100 \%$ and selectivity $100 \%$.( figure 6) (table 7 

Table (1): Demographic data of the cases included in the study

\begin{tabular}{lll}
\hline Items & Cases $(\mathbf{n}=\mathbf{8 0})$ \\
\hline \multirow{2}{*}{ Age (years) } & Mean $\pm \mathrm{SD}$ & $59.86 \pm 6.53$ \\
& Median (min-max) & $59(49-76)$ \\
BMI $\left(\mathrm{kg} / \mathrm{m}^{2}\right)$ & Mean $\pm \mathrm{SD}$ & $26.25 \pm 3.39$ \\
Sex & Median (min-max) & $25.9(20-33)$ \\
Males & & \\
Females & & $\mathbf{7 0}(\mathbf{9 0 \%})$ \\
\hline
\end{tabular}

Table (2): Classification of COPD according to severity of obstruction

\begin{tabular}{|c|c|c|c|c|c|c|}
\hline & $\begin{array}{l}\text { Control } \\
\text { group }[N=20]\end{array}$ & $\begin{array}{l}\text { Group A } \\
{[\mathbf{N}=\mathbf{2 0}]}\end{array}$ & $\begin{array}{l}\text { Group B } \\
{[\mathrm{N}=\mathbf{2 0}]}\end{array}$ & $\begin{array}{l}\text { Group C } \\
{[\mathbf{N}=\mathbf{2 0}]}\end{array}$ & $\begin{array}{l}\text { Group D } \\
{[\mathbf{N}=\mathbf{2 0}]}\end{array}$ & Test of Sign. \\
\hline Age (years) & $46.60 \pm 12.35$ & $56.15 \pm 6.31$ & $62.95 \pm 8.30$ & $60.75 \pm 4.13$ & $59.60 \pm 5.09$ & $\begin{array}{l}\mathrm{F}=13.553 \\
\mathrm{P}<0.001 *\end{array}$ \\
\hline BMI $\left(\mathrm{Kg} / \mathrm{m}^{2}\right)$ & $25.50 \pm 2.99$ & $26.69 \pm 1.96$ & $25.27 \pm 2.63$ & $27.11 \pm 4.35$ & $25.97 \pm 4.01$ & $\begin{array}{l}F=1.108 \\
P=0.358\end{array}$ \\
\hline Smoking index & NA & $40(17-90)$ & $66(26-90)$ & $68(34-76)$ & $77.5(34-120)$ & $\begin{array}{l}\mathrm{F}=55.023 \\
\mathrm{P}<0.001 *\end{array}$ \\
\hline Smoking & & & & & & \\
\hline Current smoker & None & $7(15 \%)$ & $6(13 \%)$ & $17(37 \%)$ & $15(33 \%)$ & $\begin{array}{l}\chi^{2}=95.749 \\
\mathrm{P}<0.001 *\end{array}$ \\
\hline Non smoker & $20(100 \%$ & $3(50 \%)$ & $1(17 \%)$ & $2(33 \%)$ & $0(0 \%)$ & \\
\hline
\end{tabular}

BMI (body mass index). 
Benha medical journal vol. 38, issue 1, 2021

Table (3): Classification of COPD according to severity of obstruction as regard FEV1, exacerbation per year, mMRC and CAT.

\begin{tabular}{|c|c|c|c|c|c|}
\hline & $\begin{array}{l}\text { Group A } \\
{[\mathbf{N}=\mathbf{2 0}]}\end{array}$ & $\begin{array}{l}\text { Group B } \\
{[\mathbf{N}=\mathbf{2 0}]}\end{array}$ & $\begin{array}{l}\text { Group C } \\
{[N=20]}\end{array}$ & $\begin{array}{l}\text { Group D } \\
{[\mathbf{N}=\mathbf{2 0}]}\end{array}$ & Test of Sig. \\
\hline FEV1 (L) & $2.45 \pm 0.12$ & $1.67 \pm 0.44$ & $2.27 \pm 0.14$ & $1.22 \pm 0.22$ & $\begin{array}{l}\mathrm{F}=93.044 \\
\mathrm{P}<0.001 *\end{array}$ \\
\hline \multicolumn{6}{|c|}{ exacerbations in past year } \\
\hline $\begin{array}{l}\text { Non } \\
\text { exacerbations }\end{array}$ & $5(25 \%)$ & $4(20 \%)$ & $0(0 \%)$ & $0(0 \%)$ & $\begin{array}{c}\mathrm{FET}=5.308 \\
\mathrm{P}=0.045^{*}\end{array}$ \\
\hline 1 time & $15(75 \%)$ & $16(80 \%)$ & $15(75 \%)$ & $0(0 \%)$ & $\begin{array}{c}\mathrm{FET}=23.624 \\
\mathrm{P}<0.001^{*}\end{array}$ \\
\hline 2 times & $0(0 \%)$ & $0(0 \%)$ & $5(25 \%)$ & $11(55 \%)$ & $\begin{array}{c}\mathrm{FET}=16.227 \\
\mathrm{P}<0.001^{*}\end{array}$ \\
\hline 3 times & $0(0 \%)$ & $0(0 \%)$ & $0(0 \%)$ & $7(35 \%)$ & $\begin{array}{c}\mathrm{FET}=6.132 \\
\mathrm{P}=0.029^{*}\end{array}$ \\
\hline 4 times & $0(0 \%)$ & $0(0 \%)$ & $0(0 \%)$ & $2(10 \%)$ & $\begin{array}{c}\mathrm{FET}=0.648 \\
\mathrm{P}=0.754\end{array}$ \\
\hline \multicolumn{6}{|l|}{ mMRC } \\
\hline Grade 1 & $20(100 \%)$ & $0(0 \%)$ & $20(100 \%)$ & $0(0 \%)$ & $\begin{array}{c}\mathrm{FET}=46.384 \\
\mathrm{P}<0.001^{*}\end{array}$ \\
\hline Grade 2 & $0(0 \%)$ & $16(80 \%)$ & $0(0 \%)$ & $3(15 \%)$ & $\begin{array}{c}\mathrm{FET}=27.347 \\
\mathrm{P}<0.001^{*}\end{array}$ \\
\hline Grade 3 & $0(0 \%)$ & $4(20 \%)$ & $0(0 \%)$ & $12(60 \%)$ & $\begin{array}{c}\mathrm{FET}=21.573 \\
\mathrm{P}<0.001^{*}\end{array}$ \\
\hline Grade 4 & $0(0 \%)$ & $0(0 \%)$ & $0(0 \%)$ & $5(25 \%)$ & $\begin{array}{c}\mathrm{FET}=5.648 \\
\mathrm{P}=0.041^{*}\end{array}$ \\
\hline CAT & $7.95 \pm 1.05$ & $21.60 \pm 4.60$ & $8.35 \pm 0.81$ & $28.35 \pm 3.72$ & $\begin{array}{l}\mathrm{F}=221.808 \\
\mathrm{P}<0.001^{*}\end{array}$ \\
\hline
\end{tabular}

FEV1(forced expiratory volume), mMRC (modified medical research council),CAT (COPD Assessment Test )

Table (4): Comparison between studied groups as regard to diaphragmatic thickness, thickness fraction and diaphragmatic excursion.

\begin{tabular}{|c|c|c|c|}
\hline & COPD group $[N=80]$ & Control group $[\mathrm{N}=20]$ & Test of Sig. \\
\hline $\begin{array}{l}\text { Diaphragmatic thickness } \\
\text { TLC }(\mathbf{m m})\end{array}$ & $4.45 \pm 0.60$ & $5.36 \pm 0.42$ & $\begin{array}{c}\mathrm{t}=6.373 \\
\mathrm{P}<0.001 *\end{array}$ \\
\hline $\begin{array}{l}\text { Diaphragmatic thickness } \\
\text { FRC }(\mathbf{m m})\end{array}$ & $2.50 \pm 0.23$ & $2.71 \pm 0.24$ & $\begin{aligned} \mathrm{t} & =3.652 \\
\mathrm{P} & <0.001^{*}\end{aligned}$ \\
\hline $\begin{array}{l}\text { Diaphragm thickness fraction } \\
\text { (TF) }\end{array}$ & $0.79 \pm 0.21$ & $1.02 \pm 0.15$ & $\begin{aligned} \mathrm{t} & =4.050 \\
\mathrm{P} & <0.001 *\end{aligned}$ \\
\hline
\end{tabular}


Table (5): Comparison between studied groups as regard to diaphragmatic thickness and thickness fraction.

\begin{tabular}{|c|c|c|c|c|c|c|}
\hline & $\begin{array}{l}\text { Control group } \\
{[\mathrm{N}=20]}\end{array}$ & $\begin{array}{l}\text { Group A } \\
{[\mathbf{N}=\mathbf{2 0}]}\end{array}$ & $\begin{array}{l}\text { Group B } \\
{[\mathbf{N}=\mathbf{2 0}]}\end{array}$ & $\begin{array}{l}\text { Group C } \\
{[\mathbf{N}=\mathbf{2 0}]}\end{array}$ & $\begin{array}{l}\text { Group D } \\
{[\mathbf{N}=\mathbf{2 0}]}\end{array}$ & Test of Sig. \\
\hline $\begin{array}{l}\text { diaphragmatic } \\
\text { thickness } \\
\text { TLC }(\mathbf{m m})\end{array}$ & $5.36 \pm 0.42$ & $5.16 \pm 0.19$ & $4.18 \pm 0.50$ & $4.45 \pm 0.39$ & $3.97 \pm 0.46$ & $\begin{array}{l}\mathrm{F}=45.181 \\
\mathrm{P}<0.001^{*} \\
\mathrm{P} 1=0.922 \\
\mathrm{P} 2=0.001^{*} \\
\mathrm{P} 3<0.001^{*} \\
\mathrm{P} 4<0.001^{*}\end{array}$ \\
\hline $\begin{array}{l}\text { diaphragmatic } \\
\text { thickness } \\
\text { FRC }(\mathbf{m m})\end{array}$ & $2.71 \pm 0.24$ & $2.57 \pm 0.16$ & $2.32 \pm 0.23$ & $2.37 \pm 0.15$ & $2.30 \pm 0.33$ & $\begin{array}{l}\mathrm{F}=5.507 \\
\mathrm{P}<0.001^{*} \\
\mathrm{P} 1=0.515 \\
\mathrm{P} 2<0.001^{*} \\
\mathrm{P} 3<0.001^{*} \\
\mathrm{P} 4<0.001^{*}\end{array}$ \\
\hline $\begin{array}{l}\text { diaphragm } \\
\text { thickness } \\
\text { fraction (TF) }\end{array}$ & $1.02 \pm 0.15$ & $0.98 \pm 0.10$ & $0.66 \pm 0.13$ & $0.87 \pm 0.09$ & $0.58 \pm 0.11$ & $\begin{array}{l}\mathrm{F}=55.037 \\
\mathrm{P}<0.001 * \\
\mathrm{P} 1=0.998 \\
\mathrm{P} 2<0.001 * \\
\mathrm{P} 3=0.032^{*} \\
\mathrm{P} 4<0.001 *\end{array}$ \\
\hline
\end{tabular}

$\mathrm{P}=$ Represents differences within the COPD subgroups

$\mathrm{P} 1=$ Represents differences between control group and Group A

P2= Represents differences between control group and Group B

$\mathrm{P} 3=$ Represents differences between control group and Group C

P4= Represents differences between control group and Group D

Table (6): statistical comparison between different ultra-sonographic parameter to differentiate between control \& all COPD patients.

Diaphragmatic

Thickness fraction

\begin{tabular}{lc}
\hline AUC & 0.811 \\
Cut off point & 0.927 \\
Sensitivity & $75.0 \%$ \\
Specificity & $80.0 \%$ \\
PPV & $93.7 \%$ \\
NPV & $44.4 \%$ \\
P value & $<0.001 *$ \\
\hline
\end{tabular}

PPV: positive predictive value; NPV: negative predicted value 
Benha medical journal vol. 38, issue 1, 2021

Table (7): Diaphragmatic thickness Roc curve for all groups

\begin{tabular}{llllllc}
\hline & Cutoff point & sensitivity & Specificity & PPV & NPV & P value \\
\hline Group A & 0.98 & $70 \%$ & $40 \%$ & $48 \%$ & $76 \%$ & 0.839 \\
Group B & 0.87 & $95 \%$ & $95 \%$ & $95 \%$ & $90 \%$ & $<0.001^{*}$ \\
Group C & 0.88 & $60 \%$ & $95 \%$ & $90 \%$ & $85 \%$ & $<0.003^{*}$ \\
Group D & 0.83 & $100 \%$ & $100 \%$ & $100 \%$ & $100 \%$ & $<0.001^{*}$ \\
\hline
\end{tabular}

PPV: positive predictive value; NPV: negative predicted value

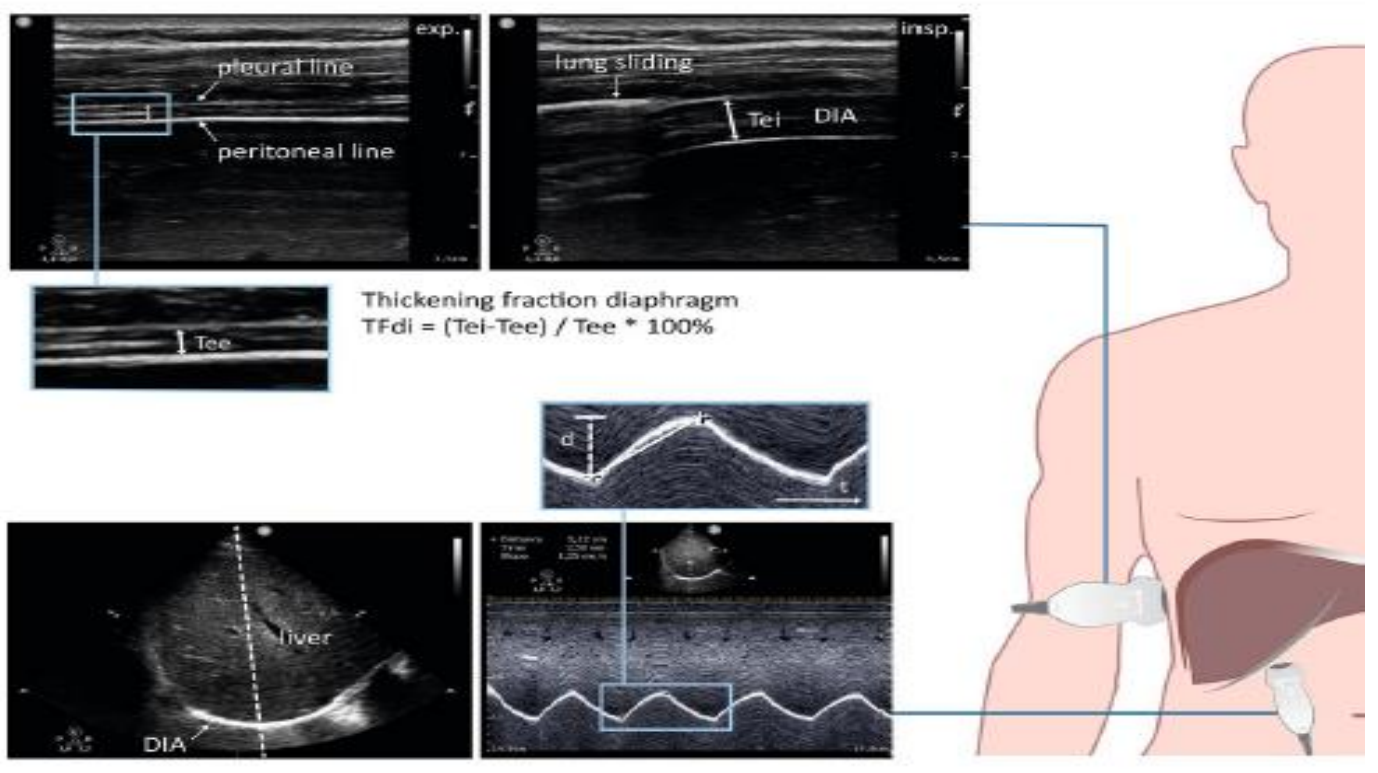

Fig (1)

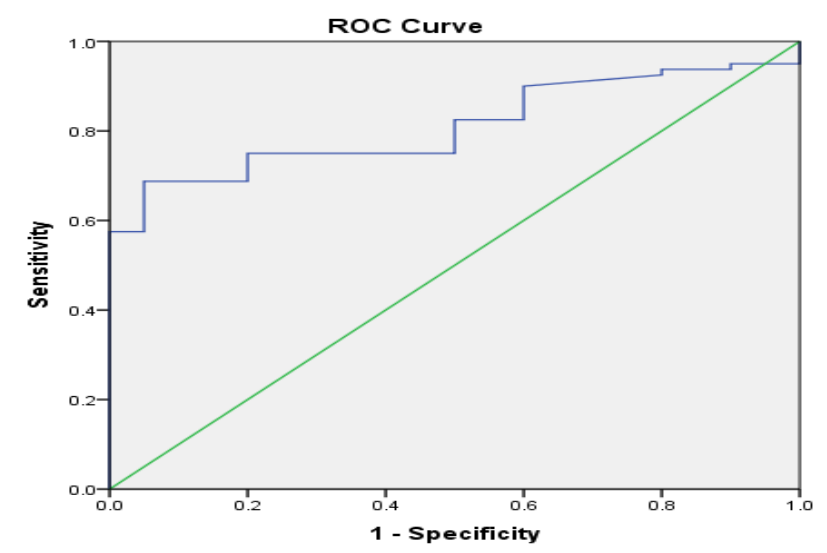

Fig (2): Roc curve of diaphragmatic thickness fraction for COPD patients. 


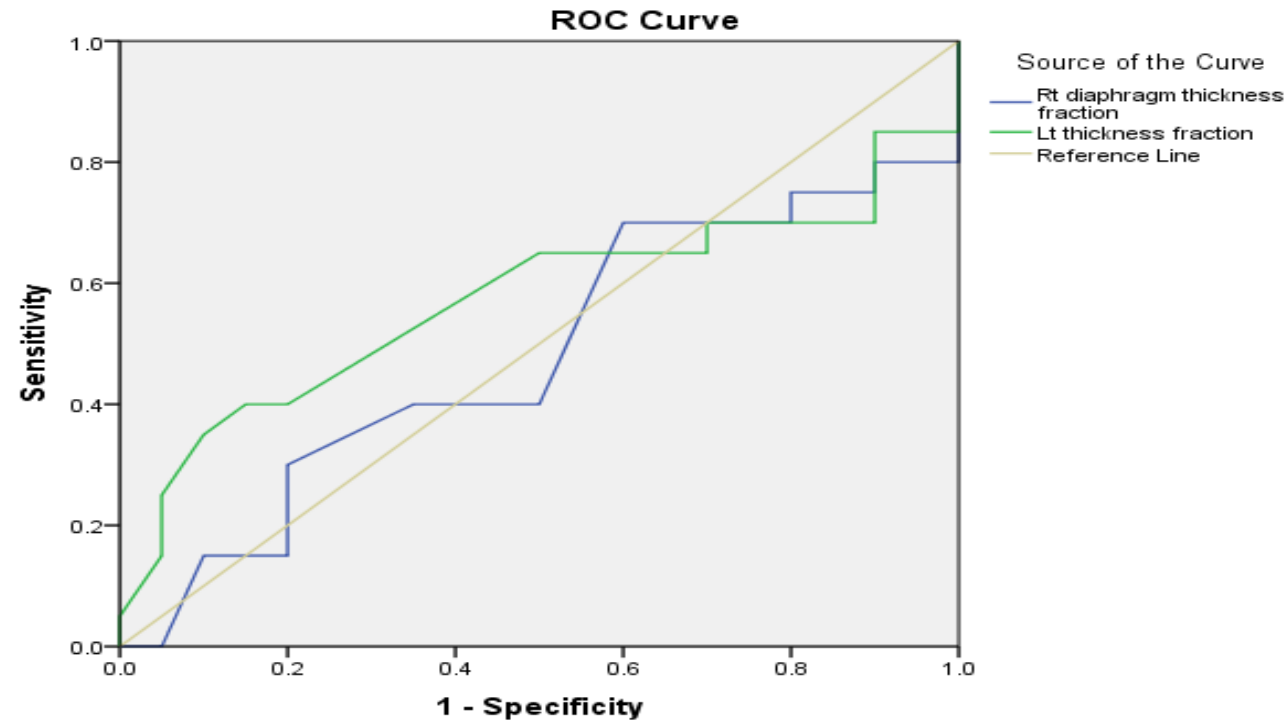

Figure (3): Roc curve group A copd (diaphragmatic thickness fraction)

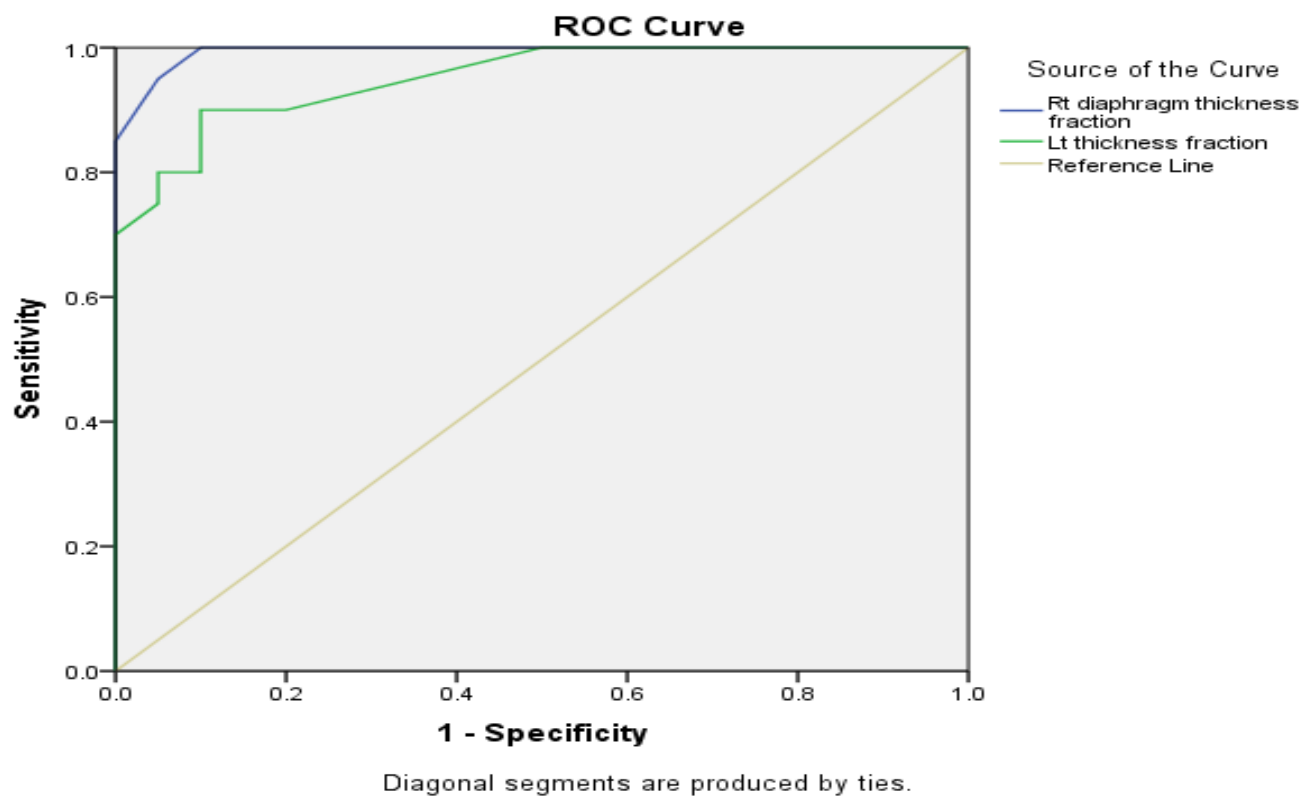

Figure (4): Prediction of ability of Diaphragm thickness fraction to differentiate between control \& group B 


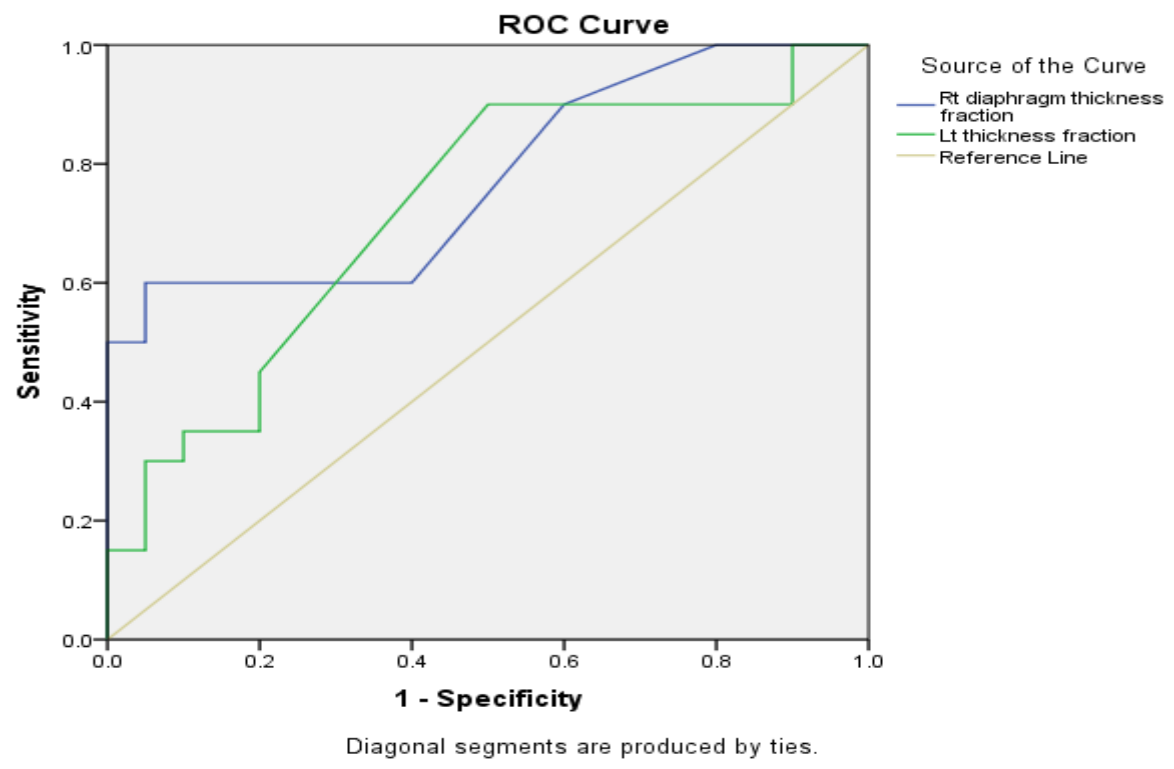

Figure (5): Prediction of ability of Diaphragm thickness fraction to differentiate between control \& group C

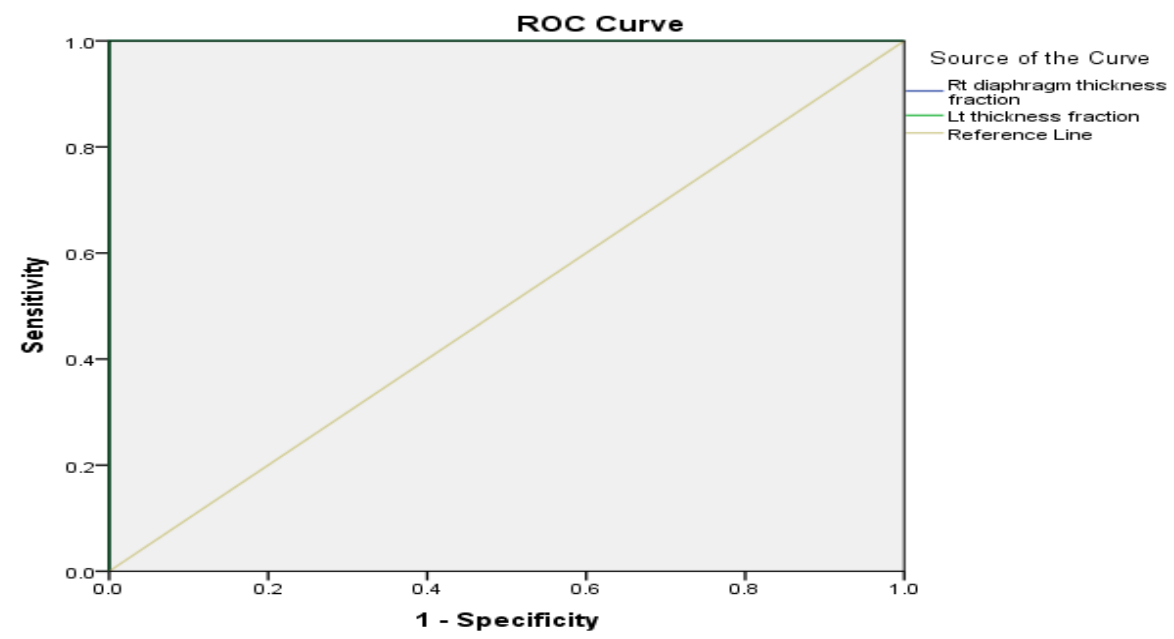

Figure (6): Prediction of ability of Diaphragm thickness fraction [on the left and right side] to differentiate between control \& group D

\section{Discussion}

The use of ultrasound to evaluate the respiratory muscle pump function is relatively new; Diaphragm ultra-sonographic evaluation provides an important first step towards improving the detection of diaphragm dysfunction as well as a protective and supportive strategy for its management (8).
The diaphragm may present normal function; reduced mobility or weakness; or loss of function or paralysis. Different ultrasound methods can be used to monitor diaphragm function - excursion, and thickness, and the use of one method does not exclude the use of another (9). With recent advent of portable 
ultrasound machines, which is available, bedside technique, safe, and relative cheap, ultrasound has become an important tool for assessment copd severity in chest outpatient clinics (10).

In current study and in a comparison between all COPD patients and control subjects as shown in table (1) ,there was a statistical significance difference between COPD group (80 patients) and control group(20 subjects) as regard diaphragmatic thickness at (TLC and FRC), diaphragmatic thickness fraction (TF),tidal excursion and max excursion ( $\mathrm{P}$ value $<0.001 *)$

This was in agreement with several studies that reported the ultra-sonographic measurement of diaphragmatic movement was useful and reliable in demonstrating diaphragmatic dysfunction in patients with COPD. (11) Similarly, another studies observed reduced diaphragmatic mobility in patients with COPD compared to healthy controls. Patients with lower diaphragmatic mobility were more dyspneic and had shorter 6-min walk distances. (12)

In contrast, other studies were against this study as measured diaphragmatic thickness by ultrasonography in 50 COPD patients and 150 healthy controls and reported the absence of a significant difference in diaphragmatic thickness between the COPD patients and the controls. This study did not investigate the relationship of diaphragmatic thickness with clinical characteristics. (13)

In addition, similar studies did not identify a significant difference between diaphragmatic thickness fraction and disease severity, symptom severity, frequency of episodes, FEV1 value, and BMI. (14)

In current study for assessment of diaphragmatic function in each COPD subgroup, diaphragmatic thickness at TILC $(\mathrm{mm}), \quad$ FRC $(\mathrm{mm})$, and diaphragmatic thickness fraction, were a statistically significant different compared to control group except for group A, moreover, COPD subgroups A, B, C and D showed significant reduction compared to each other associated with increased reduction with severity increasing which was more obvious in group $\mathrm{D}(\mathrm{P}<0.001)$.

These results were in agreement with similar one who reported a significant reduction in US-measurements of diaphragmatic thickness in patients with COPD compared with healthy subjects. (15), also another explained that defective diaphragmatic thickness in ultrasound mostly secondary to hyperinflation that could be owing to worsening of the length-tension relationship decreased length of the zone of opposition, flattening of the 
diaphragm with decrease in its curvature, which is more in moderate, and sever COPD patients. (16)

On other hand, these results were against those who found no correlation between diaphragmatic thickness in patients with COPD and pulmonary function tests except for FEV1\% of predicted in patients with mild COPD, and no correlations between diaphragmatic muscle thickness and symptom scores. However, there study did not include a control group and Radiologists performing BMode US was blind to the patient groups. (17)

In addition, studies reported increased diaphragm thickness in patients with COPD compared with healthy subjects at baseline $(0.22 \pm 0.07(\mathrm{~cm})$ vs $0.26 \pm 0.06(\mathrm{~cm}), \mathrm{p}=0.03)$ with no significant link between rate of diaphragmatic thinning and COPD diagnosis $(\mathrm{p}=0.36)$ and reported no significant difference in diaphragm thickness between patients with COPD and healthy subjects; However, all of their patients were in Groups $\mathrm{C}$ and D, moderate and severe COPD patients, and most of them had clinical/radiological evidence of hyperinflation. (18)

In a statistical comparison between different ultra-sonographic parameter to differentiate between control \& all COPD patients as shown in table (6), the cut-off point to differentiate between copd groups and control group as regard to thickness fraction was $0.927 \mathrm{~cm}$ with sensitivity $75 \%$ and specificity $80 \%$.(figure 2)

In this study, the cut-off point of TF in-group A was 0.89 with sensitivity $70 \%$ and specificity $40 \%$, while the cut-off point of $\mathrm{TF}$ in-group B was 0.87 with sensitivity $95 \%$ and specificity $95 \%$, the cut-off point of TF ingroup $\mathrm{C}$ was 0.83 with sensitivity $100 \%$ and specificity $100 \%$, and the cut-off point of TF in-group D was 0.88 with sensitivity and specificity $100 \%$.

Similar study evaluated various methods to assess the diaphragm, diaphragmatic thickness, side-to-side variation, and diaphragmatic velocity. In their study, they used cut-off value of less than $0.2 \mathrm{~cm}$ of diaphragm thickness, measured at the end of expiration, to define diaphragmatic atrophy. (19)

\section{Conclusion}

TUS (transthorathic ultrasound) is anon invasive, simple and available bedside diagnostic tool for examination in outpatient clinic and RCU patients. TUS has a better diagnostic performance for diagnosis of 
diaphragmatic dysfunction in copd patients and its relation to severity.

Measuring diaphragmatic thickness fraction is more accurate than measuring diaphragmatic thickness alone for evaluation of diaphragm in copd patients. For sure, assessment of diaphragmatic function, measuring of diaphragmatic excursion should be included.

\section{Reference:}

1. Maltais F, Decramer M, Casaburi R. An official American Thoracic Society/European Respiratory Society statement: update on limb muscle dysfunction in chronic obstructive pulmonary disease. Am J Respir Crit Care Med 2014;189:e1562.

2. Anthonisen NR, Skeans MA, Wise RA, Manfreda J, Kanner RE, Connett JE et al., Lung Health Study Research Group. The effects of a smoking cessation intervention on 14.5-year mortality: a randomized clinical trial. Ann Intern Med. 2005 Feb $15 ; 142(4): 233-9$..

3. Santana A and de Albuquerque P. Respiratory muscles in COPD: be aware of the diaphragm. J Bras Pneumo; 2018;44(1):1-2

4. Dos Santos Yamaguti WP, Paulin E, Shibao S, Chammas MC. Air trapping: The major factor limiting diaphragm mobility in chronic obstructive pulmonary disease patients. Respirology 2008; 13: 138-44.

5. Lopez-Navas K, Brandt S and Strutz M (2012): Comparison of two methods to assess transdiaphragmatic pressure at different levels of work of breathing. Biomed Tech. DOI: 10.1515/bmt-2012- 4124.
6. Haaksma ME, Atmowihardjo L, Heunks L, Spoelstra-de Man A, Tuinman PR. Ultrasound imaging of the diaphragm: facts and future. A guide for the bedside clinician. Neth $J$ Crit Care. 2018;26:58-63

366 E, MekontsoDessap A, Dimassi uragm ultrasonography to estimate the work of breathing during non-invasive ventilation. Intensive Care Med 2012;38:796-803. doi: 10.1007/s00134-012-2547-7.

8. Goligher EC, Laghi F, Detsky ME, Farias P, Murray A, Brace D et al., Measuring diaphragm thickness with ultrasound in mechanically ventilated patients: feasibility, reproducibility and validity (vol 41, pg 642, 2015) Intens Care Med. 2015;41:734

9. Kohansal R, Martinez-Camblor P, Agusti A, Buist AS, Mannino DM, Soriano JB. The natural history of chronic airflow obstruction revisited: an analysis of the Framingham offspring cohort. Am J Respir Crit Care Med 2009; 180(1): 3-10.

10. Saraogi A; Lung ultrasound: present and future lung India, 32, pp. 250-257.

11. Scheibe N, Sosnowski N, Pinkhasik A, Vonderbank S, Bastian A. Sonographic evaluation of diaphragmatic dysfunction in COPD patients. International Journal of Chronic Obstructive Pulmonary Disease 2015; 10 (1): 1925-1930. doi: 10.2147/ COPD.S85659

12. Paulin E, Yamaguti WP, Chammas MC, Shibao S, Stelmach R. Influence of diaphragmatic mobility on exercise tolerance and dyspnea in patients with COPD. Respiratory Medicine 2007; 101 (10): 2113-2118. doi: 10.1016/j.rmed.2007.05.024.

13. Baria MR, Shahgholi L, Sorenson EJ, Harper CJ, Lim K. B-mode ultrasound assessment of diaphragm structure and function in patients with 
COPD. Chest 2014; 146 (3): 680-685. doi: 10.1378/chest.13-2306

14. Eryüksel E, Cimsit C, Bekir M, Cimsit Ç, Karakurt S. Diaphragmatic thickness fraction in subjects at high-risk for COPD exacerbations. Respiratory Care 2017; 62 (12): 1565- 1570. doi: 10.4187/respcare.05646

15. Jain S, Nair G, Nuchin A. Study of the diaphragm in chronic obstructive pulmonary disease using ultrasonography. Lung India 2019;36:299-303

16. De Troyer A, Wilson TA. Effect of acute inflation on the mechanics of the inspiratory muscles. J Appl Physiol Bethesda Md 2009; 107:315-323.

17. Cimsit C, Bekir M, Karakurt S, Eryuksel E. Ultrasound assessment of diaphragm thickness in COPD. Marmara Med J 2016; 29:8-13.

18. Ogan N, Aydemir Y, EVrin T. Diaphragmatic thickness in chronic obstructive lung disease and relationship with clinical severity parameters. Turk J Med Sci 2019;49:1073-8.

19. Sarwal A, Walker FO, Cartwright MS. Neuromuscular ultrasound for evaluation of the diaphragm. Muscle Nerve 2013;47:319-329.

To cite this article: Tarek S. Essaw, Abdelsadek H. AL-Arag, Hany H. Mousa, Mona Abd ElSattar, Rehab S. ELSawy. Ultrasound Assessment of Diaphragmatic Thickness in Chronic Obstructive Pulmonary Disease Patients as A predictor for Disease Severity. BMFJ 2021; 38(1): 353-367. DOI: 10.21608/bmfj.2021.62994.1384 